\title{
Bovinocultura de ciclo curto em pastagem - Revisão
}

\author{
P.H.A.A. Sousa ${ }^{1 *}$, B.S.L. Lima ${ }^{1}$, D.S. Amorim ${ }^{1}$ R.R.M. Mota ${ }^{1}$,
}

F.G.S. Alves ${ }^{2}$ M.C.C. Vieira ${ }^{3}$

${ }^{1}$ Programa de Pós-Graduaçáo em Zootecnia, Campus Professora Cinobelina Elvas, Universidade Federal do Piauí, Bom Jesus, PI, Brasil

${ }^{2}$ Programa de Pós-Graduação em Zootecnia, Campus do Pici Bloco 608, Universidade Federal do Ceará, Fortaleza, CE, Brasil ${ }^{3}$ Curso de Graduação em Medicina Veterinária, Campus Professora Cinobelina Elvas, Universidade Federal do Piauí,

Bom Jesus, PI, Brasil

* Autor correspondente: Universidade Federal do Piauí (UFPI), Rodovia BR 135, Km 03, s/n, Bairro Planalto Horizonte,

Bom Jesus, PI, CEP 64900-000. Fax (089 3562-1016) e-mail: paullo_ap1@hotmail.com

ISSN 2448-0479

Resumo - Para uma pecuária precoce e racional eficiente tem-se que, alcançar o equilíbrio biológico entre o valor forrageiro da planta, ou das plantas que compóem a pastagem, e do tipo de animal, para assim assegurar tanto a produtividade como a sustentabilidade do sistema. Assim o continuo ajuste entre as necessidades energéticas e protéicas de bovinos e a oferta de nutrientes através da pastagem e Ood bovinosrto. uplementaçorna essencialconfusa, seria melhor desta maneira: Assim o continuo ajuste entre a demanda e a fo uso estratégico de suplementação se torna essencial na pecuária de ciclo curto. Isto se consegue com um bom manejo das pastagens e o uso estratégico de suplemento. Partindo disto, esta revisão de literatura vem a objetivar fornecer informaçóes sobre a bovinocultura de ciclo curto em pastagem.

Palavras chaves - Bovino. Desempenho. Precoce. Pastejo.

Abstract - For efficient early and rational livestock one has to achieve biological balance between forage value of the plant, or plants that make up the pasture, and the type of animal, thus ensuring both productivity and sustainability of the system. Thus the continuous adjustment between energy and protein requirements of cattle and nutrient supply through grassland and strategic supplementation use becomes essential in the short-cycle livestock. This is achieved with a good pasture management and the strategic use of supplement. From this, this literature review is to objectify provide information on the cattle grazing in short cycle.

Keywords - Bovine. Grazing. Performance. Precocious.

Recebido em: 11 de maio de 2016.

Aprovado em: 03 de julho de 2016.

\section{INTRODUÇÃO}

O Brasil sendo um país de clima tropical com vasta extensão territorial, sendo uma característica importante para a pecuária brasileira na criação de bovinos de ciclo curto, pois tem-se a maior parte de seu rebanho criado a pasto (FERRAZ; FELÍCIO, 2010), que se constitui na forma mais econômica e prática de produzir e oferecer alimentos para os bovinos.

Em decorrência dessa vocação da pecuária brasileira em função das características climáticas e da extensão territorial do País, ocupa com pastagem cerca de 173 milhóes de hectares $(\sim, 117$ milhóes de hectares de pastagens cultivadas), das quais, estimase, mais de $70 \%$ estejam em algum estágio de degradação (MACEDO et al., 2013).

A pecuária de corte em sistema extensivo, a qual coloca o Brasil entre os líderes mundiais na produção de carne bovina (ANDRADE et al., 2013), sendo uma alternativa para preconizar a produção de bovino de ciclo curto em pastagem em função da produção que usam recursos nutricionais com custos relativamente baixos, como as gramíneas tropicais sob pastejo. 
Para a pecuária de ciclo curto, apresenta altos ganhos por área e produtividade acima da média nacional, algumas tecnologias tornam-se imprescindíveis no sistema, como novas variedades de plantas, novos métodos de recuperação de pastagem além da divisão do pasto em piquetes por exemplo. Sendo que na produção a pasto, a forragem é o principal alimento disponível para os animais em pastejo, devendo fornecer energia, proteína, vitaminas e minerais para assim atender às exigências de mantença e produção (TONELLO et al., 2011). Entretanto, devido às condições sazonais e dificuldades de manutenção dos pastos, muitas vezes os animais tem que ser suplementados.

A precocidade animal deve estar aliada a novas tecnologias de manejo e produção de forragens, permitindo assim uma boa lucratividade, como também a sustentabilidade do sistema. Dessa forma, o uso da suplementação protéica-energética durante o período das águas pode ser viável quando se objetiva manter uma curva de crescimento contínua visando abates mais precoces (OLIVEIRA et $a, l$ 2015).

Sendo assim, quando se trata de lucratividade em bovinocultura de corte, deve-se preconizar a produção sob pastejo, considerando o pasto como o alimento natural dos ruminantes, o mesmo deve constituir o principal componente da dieta. (POTTER et al., 2010)

Os programas de melhoramento genético se intensificaram e multiplicaram-se os produtores de animais com maior capacidade de transferir aos descendentes certas características desejadas, como por exemplo a rusticidade. O clima tropical, com elevada quantidade de iluminaçấo solar e pluviosidade, é ideal para a produtividade vegetal, por isso o país é abundante em pastagens naturais e possui características ideais para pastagens cultivadas (SANTOS et al., 2010).

Diante o exposto, objetivou-se com esta revisão de literatura fornecer informaçóes e subsídios sobre a bovinocultura de ciclo curto em pastagem

\section{REVISÃO}

\subsection{Bovinocultura em sistema a pasto}

A bovinocultura de corte é uma atividade econômica de grande interesse para o país. Atualmente o Brasil possui um rebanho aproximado de $210 \mathrm{mi}-$ lhôes de cabeças, sendo o maior produtor de carne, ficando atrás somente dos Estados Unidos da América (BRASIL, 2014) e, grande parte do rebanho brasilei- ro é criado em sistema extensivo de produção, sendo a alimentaçáo à base de pasto e estima-se que apenas $3 \%$ do rebanho são terminados em sistema intensivo.

De acordo com dados da Associação Brasileira das Indústrias Exportadoras de Carne a quantidade de carne industrializada exportada em 2015 foi de 106,216 toneladas contra 1078,184 toneladas de carne in natura (ASSOCIAÇÃO BRASILEIRA DAS INDÚSTRIAS EXPORTADORAS DE CARNE, 2016). Portanto, técnicas de intensificação que permitam o aumento da produtividade da criação de bovinos sob pastejo, devem ser consideradas, pois tornam-se uma ferramenta para otimizar o uso racional dos recursos disponíveis, que possibilitem incrementos na receita final de maneira eficiente e sustentável.

Para atender a pecuária precoce e racional tem que se alcançar o equilíbrio biológico entre o animal e o pasto, para assegurar tanto a produtividade como a sustentabilidade do sistema. Uma vez que a pastagem se encontra com deficiência, o animal em pastejo, não consegue usufruir adequadamente dos constituintes nutricionais do pasto (FERNANDES, L. et al., 2010). Essa situação tende a piorar no período da seca, quando as forrageiras completam seu ciclo de crescimento com a emissão das inflorescências, reduzindo a relação folha/caule, e por consequência os animais tem um aumento na idade de abate.

Nesse contexto, para garantir o bom desempenho animal em sistemas de produção em pasto de ciclo curto, deve haver um ajuste nutricional entre a curva sazonal de oferta das pastagens com a curva crescente da demanda por nutrientes. Com o intuito de equilibrar o sistema de produção, a suplementação alimentar pode ser uma ferramenta tecnológica essencial que garanta esse aporte de nutrientes exigidos pelos animais (HOFFMANN et al., 2014).

\subsection{Suplementaçáo de bovinos em pastejo}

Quando se almeja uma pecuária de ciclo curto com altos ganhos por área e produtividade acima da média nacional, algumas tecnologias tornam-se fundamentais no sistema como, um bom manejo de pastagem, divisão do pasto em piquetes, adubação e irrigação caso necessário no que se refere a produção de bovinos em pastejo. A forragem sendo o único alimento disponível para os animais em pastejo, deve fornecer energia, proteína, vitaminas e minerais para atender às exigências para mantença e produção. Já o suplemento, deve ser considerado como um complemento da dieta, o qual deve su- 
prir os nutrientes deficientes da forragem disponível (TONELLO et al., 2011).

Dessa maneira, os fatores mais importantes ligados ao pasto, são a oferta de forragem potencialmente digestível, que envolve a estrutura do pasto (massa de forragens, altura do pasto, relação folha/colmo, entre outros) e sua qualidade (sendo a composição nutricional e a digestibilidade os principais fatores). Em relaçáo ao suplemento salientam-se a quantidade e o tipo de suplemento (proteico ou energético) a ser fornecido ao animal (VALADARES FILHO et al., 2010).

Suplementar um rebanho criado a pasto pode permitir a reduçáo no tempo necessário para a terminação dos animais e diminuir os custos de produção. Dentre as vantagens produtivas, como aumento na taxa de lotaçáo, desocupaçáo de áreas para entradas de animais mais jovens, aumento de taxa de desfrute e planejamento para venda em momentos mais oportunos, estão entre as de maior impacto (SILVA et al., 2010).

\subsection{Características das pastagens tropicais}

A produçáo de bovinos de corte no Brasil está consolidada com o uso das pastagens, regida por dois períodos distintos, o período seco e o período das chuvas, principalmente na região próxima a linha do equador (PORTO et al., 2009).

O manejo de pastejo objetiva maximizar a transformação da forragem produzida em produto animal, mantendo-se a perenidade do pasto, através da contínua emissão de folhas e perfilhos após o pastejo, restaurando a área foliar da planta. Para isso, é essencial o conhecimento da dinâmica dos processos de crescimento e desenvolvimento das plantas que compóem a pastagem (CASAGRANDE et al., 2011).

A disponibilidade e a qualidade das forrageiras são influenciadas pela espécie e cultivares, pelas propriedades químicas e físicas do solo, pelas condiçôes climáticas, pela idade fisiológica e pelo manejo a que a forrageira é submetida (EUCLIDES, 2001). Sendo assim, a melhor eficiência da utilização das forrageiras dependerá desse conjunto de fatores e de sua manipulação adequada que proporcionará maior produção animal.

As forrageiras tropicais, em consequência das estaçôes climáticas, não fornecem quantidades suficientes de nutrientes para a produçáo máxima dos animais. $\mathrm{Na}$ época das águas verifica-se alta produção de forragem obtendo-se $85 \%$ da produção anual, com qualidade nutricional adequada, enquanto que, durante a época da seca observa-se limitaçôes quanti- tativa e qualitativa. (FERNANDES, W. et al., 2010).

A digestibilidade das forrageiras pode variar de $60 \%$ no período das águas a $40 \%$ no período seco, devido ao aumento no teor de lignina e de fibra na planta, e o teor de proteína pode variar de $10-12 \%$ (período das águas) no início do crescimento vegetativo a $2-4 \%$ (período da seca) no final do ciclo, após a floração. Van Soest, (1994), demonstrando que forrageiras tropicais apresentam baixo valor nutritivo no período seco, com teores de proteína bruta $(\mathrm{PB})$ inferiores ao mínimo de 7,0\% na matéria seca (MS), limitando a atividade dos microrganismos ruminais (SORIANO et al., 2013).

\subsection{Estratégias nutricionais e manejo de pastagens em diferentes estaçóes}

É de fundamental importância que os princípios de manejo sejam conhecidos e praticados para que as pastagens possam se manter produtivas e persistentes. A constituição genética da planta define seu potencial produtivo, no entanto, o manejo é o responsável pela sua expressão. A produção de forragem se dá em funçáo do meio, da temperatura e da radiação e é limitada pela disponibilidade de fatores manejáveis, basicamente, nutrientes e água. (FERNANDES et al., 2015)

A remoção de parte dessa limitação pela introdução de insumos tais como fertilizantes e irrigação, vai depender do clima e, obviamente, da relaçáo custo -benefício. Os custos dificilmente podem ser alterados para um dado nível de insumos e, por isso devem-se concentrar esforços em maximizar os benefícios, ou seja, otimizar a produção. Dessa forma, há necessidade de se buscar aumento de produtividade, o que pode ser alcançado pelo incremento da capacidade de suporte das pastagens e/ou pela melhoria do desempenho produtivo de cada animal (EUCLIDES, 2001).

O manejo adequado das pastagens deve contemplar o equilíbrio entre o rendimento e a qualidade da forragem produzida, simultaneamente à produção ótima por animal e por área, numa perspectiva sustentável (COLEMAN, 1992). A oferta de forragem interfere simultaneamente em todos estes aspectos e é um dos critérios recomendados para definir o manejo das pastagens.

No início da estação das chuvas há uma rejeição da forragem seca pelos animais, que preferem as brotaçóes novas, ainda escassas e insuficientes para atender o consumo. Assim, as áreas de pastejo devem ser reservadas para rebrota, após serem subme- 
tidas a pressão de pastejo intensa para retirada dos resíduos de forragem remanescentes. (SILVA-MARQUES et al., 2015)

Os efeitos do pastejo sobre a dinâmica vegetal acontecem em diversos níveis dentro de uma escala de tempo. Em curto prazo, desfolhaçôes diferentes, comandados pela preferência e seletividade animal, atrelados com a resistência de pastejo de cada espécie, podem mudar a composição botânica de uma pastagem (SCHÖNBACK et al., 2010).

O emprego de suplementos na estação seca adquire enfoque diferenciado, suprindo as exigências pelos nutrientes limitantes, compensando a baixa qualidade das forrageiras. Ao provê-los, desde que em quantias que atendam às exigências dos animais obtêm-se a manutenção ou ganho de peso nos animais dependendo dos objetivos traçados para o sistema de produção. Dessa maneira, considerando o pasto como a fonte de energia mais barata, de acordo com Paulino et al., (2002), deve-se considerar os custos de suplementação e as consequências da subnutrição.

\subsection{Desempenho animal}

O desempenho animal sob pastejo, é condicionado por diferentes fatores, como: genética animal, consumo de forragem, valor nutritivo da forragem e eficiência na conversão da forragem consumida. Dessa maneira as características intrínsecas das plantas forrageiras devem ser levadas em consideração, para melhorar o desempenho dos animais, a fim de garantir a lucratividade do sistema (HOFFMANN et al, 2014).

No entanto, a produtividade e qualidade dessas gramíneas sofrem variaçōes sazonais ao longo do ano devido às condições climáticas, permitindo desempenho inconstante dos animais ao longo do ano, resultando em baixos índices zootécnicos (PAULINO; DETMANN; VALADARES FILHO, 2008).

Devido o desempenho dos animais submetidos apenas a alimentação a pasto não ser tão satisfatório, é necessário o fornecimento de suplementos concentrados, considerando sempre o ponto de vista técnico-econômico.

Tendo em vista que a correção das deficiências nutricionais do pasto, via suplementação, permitem um melhor desempenho e propiciam a redução do ciclo de produçáo e da idade de abate dos animais, a suplementação se torna um fator preponderante na produção de bovinos criados a pasto. Isso devido principalmente por decorrência dos efeitos adicionais da suplementação como aumento da microbiota ru- minal, da digestão da fibra no rúmen e, consequentemente, do consumo de pasto, comumente chamado de efeito aditivo (ZERVOUDAKIS et al., 2001).

As forrageiras tropicais, em geral, apresentam limitações nutricionais em relação às forrageiras temperadas, os efeitos climáticos são as principais causa que agravam na qualidade desta forrageira, na época da seca os animais perdem peso o que é denominado de "efeito sanfona", ou seja, ocorrem altos ganhos de peso na época das águas e pouco ganho de peso na época das secas, ampliando com isso, a idade de abate (CARDOSO; VITTO; NOGUEIRA, 1998)

\section{CONCLUSÃO}

Nos países tropicais, geralmente o sistema de criação de bovinos é a pasto. Entretanto, animais exclusivamente criado a pasto podem apresentar um desempenho que pode comprometer as metas de abate, pois nesse sistema os animais são mais tardios, em virtude das dificuldades sazonais e de manutenção de pastagem.

Atualmente, o ciclo curto de produçấo é uma exigência para a pecuária, pois há uma grande demanda por carne. Sendo que a redução na idade de abate pode ser alcançada com um bom manejo das pastagens, complementada pelo fornecimento estratégico de suplementação ao animal.

\section{REFERÊNCIAS}

ANDRADE, R.G. et al. Indicativo de degradação de pastagensa partir de dados Spot Vegetation. In: SIMPÓSIO BRASILEIRO DE SENSORIAMENTO REMOTO, 16., 2013, Foz do Iguaçu, PR. Anais... Foz do Iguaçu: INPE, 2013. ASSOCIAÇÃO BRASILEIRA DAS INDÚSTRIAS EXPORTADORAS DE CARNE. Estatísticas de exportaçáo de carne. São Paulo: ABEIC, 2016. Disponível em <http://www.abiec.com.br/>. Acesso em: 27 jul. 2016.

BRASIL. Ministério da Agricultura, Pecuária e Abastecimento. [Homepage]. Disponível em: <http://www.agricultura.gov.br/>. Acesso em: $1^{\circ}$ de dezembro de 2014.

CASAGRANDE, D.R. et al. Canopy characteristics and behavior of Nellore heifers in Brachiaria brizantha pastures under different grazing heights at a continuous stocking rate. Revista Brasileira de Zootecnia, Viçosa, v. 40, n. 11, p. 2294-2301, nov. 2011.

CARDOSO, A.G.; VITTO, G.; NOGUEIRA, M.P. A importância da suplementaçáo protéica para os ani- 
mais. Revista Pecuária de Corte, São Paulo, v. 8, n. 80, p. 70-74, 1998

COLEMAN, S.W. Plant-animal interface. Journal of Production Agriculture, v. 5, p. 7-13, 1992.

EUCLIDES, V. P. B. Produçáo intensiva de carne bovina em pasto. 2001. Disponível em: <http://www.simcorte. com/index/Palestras/s_simcorte/05_valeria.PDF>. Acesso em: 25 abr 2001.

FERNANDES, L.O. et al. Efeito da suplementação no desempenho de bovinos de corte em pastagem de Brachiaria brizantha cv. Marandu. Revista Ciência e Agrotecnologia, Larvas, v. 34, n. 1, p. 240-248, jan./fev. 2010.

FERNANDES, L.O. Desempenho de bovinos da raça Gir em pastagem de Brachiaria brizantha submetidos a diferentes manejos Revista Brasileira de Saúde e Produçáo Animal, Salvador, v. 16, n. 1, p. 36-46, nov. 2015

FERNANDES, W.K. Estimativas de parâmetros genéticos para os escores visuais e suas associaçôes com peso corporal em bovinos de corte. Revista Brasileira de Zootecnia, Viçosa, v. 39, n. 5, p. 1015-1022, abr. 2010

FERRAZ, J.B.S.; FELÍCIO, P.E. Production systems: an example from Brazil. Meat Science, v. 84, n. 2, p. 238243, 2010.

HOFFMANN, A. et al. Produçáo de bovinos de corte no sistema de pasto-suplemento no período seco. Nativa, Cuiabá, v. 02, n. 02, p. 119-130, abr../jun. 2014.

MACEDO, M.C.M. et al. Degradação de Pastagens, Alternativas de Recuperação e Renovação, e Formas de Mitigação. In: ENCONTRO DE ADUBAÇÃO DE PASTAGENS DA SCOT CONSULTORIA, 1., 2013, Ribeirão Preto, SP. Anais... Bebedouro: Scot Consultoria, 2013. p. 158-181.

OLIVEIRA, F.L. et al. Desempenho de bovinos da raça Gir em pastagem de Brachiaria brizantha submetidos a diferentes manejos. Revista Brasileira de Saúde e Produçáo Animal, Salvador, v. 16, n. 1, p. 36-46 jan./mar. 2015.

PAULINO, M. F. et al. Soja grão e caroço de algodáo em suplementos múltiplos para terminação de bovinos mestiços em pastejo. Revista Brasileira de Zootecnia, Viçosa, v. 31, Supl. p. 484-491, dez. 2002.

PAULINO, M. F. et al. Bovinocultura funcional nos trópicos. In: SIMPÓSIO INTERNACIONAL DE PRODUÇÃO DE GADO DE CORTE, 2., 2008, Viçosa, MG. Anais....Viçosa, MG: SIMCORTE, 2008. v. 6, p. 275-305.
PORTO, M.O. et al. Fontes suplementares de proteína para novilhos mestiços em recria em pastagens de capim -braquiária no período das águas: desempenho produtivo e econômico. Revista Brasileira de Zootecnia, Viçosa, v. 38, n. 8, p. 1553-1560, ago. 2009.

POTTER, L. et al. Suplementação com Concentrado para novilhas de corte mantidas em pastagens cultivadas de estação fria. Revista Brasileira de Zootecnia, Viçosa, v. 39, n. 5, p. 992-1001, maio 2010.

SANTOS, M.E.R. et al. Estrutura do capim-braquiária durante o diferimento da pastagem. Acta Scientiarum. Animal Sciences, Maringá, v. 32, n. 2, p. 139-145, abr. 2010.

SORIANO, V. S. et al. Produção animal e vegetal em pastagem de Cynodon manejada sob diferentes ofertas de forragem por ovinos de dois grupos genéticos, Ciência Rural, Santa Maria, v.43, n.1, jan. 2013.

SCHÖNBACK, P. et al.Grassland responses to grazing: effects of grazing intensity and management system in an Inner Mongolian steppe ecosystem. Plant and Soil, Crawley, v. 340, p. 103- 115, apr. 2010.

SILVA, R.R. et al. Novilhos nelore suplementados em pastagens: consumo, desempenho e digestibilidade. Archivos de Zootecnia, Córdoba, v. 59 n. 228 p. 549-560, mar. 2010

SILVA-MARQUES, R.P. et al. Suplementos múltiplos para novilhas de corte a pasto no período seco: características nutricionais Semina: Ciências Agrárias, Londrina, v. 36, n. 1, p. 509-524, jan./fev. 2015.

TONELLO, C.L. et al. Suplementação e desempenho de Bovinos de corte em pastagens: tipo de forragem. Acta Scientiarum. Animal Sciences, Maringá, v. 33, n. 2, p. 199-205, ago. 2011.

VALADARES FILHO, S.C. et al. Exigências nutricionais de zebuínos puros e cruzados: BR CORTE. 2.ed. Viçosa: UFV, 2010. 193p.

ZERVOUDAKIS, J.T. et al. Desempenho e características de carcaça de novilhos suplementados no período das águas. Revista Brasileira de Zootecnia, Viçosa, v. 30, n. 4, p. 1381-1389, jul./ago. 2001. 